\title{
Evaluation of foamed bitumen efficiency in warm asphalt mixtures recycling
}

\author{
L. Abreu, J. Oliveira \& H. Silva \\ CTAC - Territory, Environment and Construction Centre, University of Minho, Guimarães, Portugal \\ D. Palha \& P. Fonseca \\ Elevo Group, Porto, Portugal
}

\begin{abstract}
The recycling of pavements is nowadays a very important question to the road paving industry. With the objective of incorporating higher percentages of reclaimed asphalt (RA) materials in recycled asphalt mixtures, new techniques have been developed in the last years. The use of foamed bitumen is normally associated with the production of cold asphalt mixtures, which usually show lower quality standards. However, the objective of the work presented in this paper is to assess the use of foamed bitumen as the binder of warm asphalt mixtures incorporating 30\% RA, which have quality standards similar to those of conventional mixtures. Thus, five mixtures have been produced with 30\% RA, one of them with a conventional bitumen (control mix) and the others with foamed bitumen at different production temperatures. The mixtures were tested for compactability and water sensitivity and the results show a possible reduction of $25^{\circ} \mathrm{C}$ in the production temperatures, while the water sensitivity test results were kept close to $90 \%$.
\end{abstract}

\section{INTRODUCTION}

Nowadays the constant concern of saving natural resources and reduce waste production is promoting an increase on the recycling of the used materials. Industries and the Society are very focused on finding the right treatment for waste materials. On the asphalt paving industries, the effort has been concentrated in the incorporation of reclaimed asphalt (RA) material in new mixtures.

The incorporation of RA have been studied by a significant number of authors with the principal objective of increasing the percentage of RA in new mixtures (Celauro et al., 2010, Shu et al., 2012, Su et al., 2009, Abreu et al., 2015). The incorporation of RA have numerous advantages, namely, the reduction of costs when compared with the production of new mixtures (Chiu et al., 2008), the reduction of space needed to dispose of the waste from pavement rehabilitation (saving money and the environment) and the reduction of the environmental impact (lower consumption of natural resources and its associated emissions).

However some disadvantages can be also pointed out to the incorporation of high percentages of RA (above 20\%). The fact that the material may be heterogeneous implies the need for a correct treatment before the incorporation in new mixtures. Some studies mention different ways to treat the RA before the incorporation in order to mitigate the effect of this issue (Aravind \& Das, 2007, Oliveira et al., 2012, Abreu et al., 2013). Other disadvantage is related with the aged bitumen present in that material that normally implies the use of a virgin bitumen softer than the conventional bitumens normally used and, in some cases, the use of rejuvenators. 
Another problem that results from the incorporation of high percentages of RA is the increase on the heating temperature of the virgin aggregates. This is due to the fact that the virgin aggregates have to be overheated in order to transfer part of the temperature to the RA material that is normally introduced in the mixing chamber at ambient temperature. Using this procedure, it is possible to mitigate the ageing effect of the temperature on the bitumen (which is already significantly aged by the time it has been exposed to oxygen and sun light in the road pavement). In recent studies, the RA material has been divided into two fractions (coarse and fine, separated in the $10 \mathrm{~mm}$ sieve) and the coarse fraction is heated together with the virgin aggregates while the fine fraction is kept at ambient temperature up to the moment it is introduced in the mixer (Abreu et al., 2015, Oliveira et al., 2012, Palha et al., 2013). The main reason that justifies this procedure is the fact that the fine fraction contains a significantly higher percentage of bitumen, which can thus be preserved from unwanted ageing, and the production rates can be increased by reducing the mixing time (needed for the temperature transfer to occur), since a higher proportion of material is heated up.

To reduce the production temperature new techniques have been recently used. The mixtures produced at lower temperatures are known as warm mix asphalt (WMA). These techniques have been pointed out as a solution to reduce energy consumption and greenhouse gas emissions, to improve the working conditions, to improve the workability of the mixtures, and to increase time available to apply and compact the mixtures (Zaumanis et al., 2012, D’Angelo et al., 2008, Rubio et al., 2012). These techniques can be classified, according to the production process, into: i) utilization of organic additives; ii) utilization of chemical additives or iii) foaming processes (Sengoz et al., 2013, Zaumanis et al., 2012, He \& Wong, 2007). In terms of foaming processes they can be differentiated between water-containing technologies, e.g., by using a synthetic zeolite, and water-based technologies where the water is directly injected into the hot bitumen (Rubio et al., 2012).

The process of injecting water into the hot bitumen originates an expansion on the bitumen known as foamed bitumen (FB). This technique can be used as a stabilizing and recycling agent with a variety of materials, which can be a good quality material or with not so appropriated materials (He \& Wong, 2006). When producing FB, the characteristics that are important to control are the expansion ratio (ER) and the half-life (HL) (Jenkins, 2000). The ER is a relation between the volume of the bitumen after expansion and the initial volume of bitumen. Normally the foamed bitumen is characterized by the maximum expansion ratio (ERmax) that represents the maximum volume obtained. The half-life (HL) is the elapsed time between the moment that the foam was at its maximum volume and the time when this volume reduces to a half of that value. It gives an idea of the time available to produce the mixture (Brennen et al., 1983). Other index that are referred to as important to analyze the results of the foaming process is the foam index (FI), that was defined by Jenkins (2000) as the area below the decay curve of a bitumen with some restrictions. The highest FI is normally associated to a better bitumen in terms of foaming characteristics. Foam promoting additives may be necessary to increase the half-life time in order to obtain an appropriate mixture (aggregates fully covered by the bitumen).

In the present paper, the possibility of using FB as a binder to produce asphalt mixtures with incorporation of 30\% RA at temperatures lower than those normally used, has been tested. The expansion characteristics of the bitumen with and without foaming additive and its basic characteristics have been evaluated and the effect of the production temperature has been assessed by testing different asphalt specimens for compactability and water sensitivity.

\section{MATERIALS AND METHODS}

\subsection{Materials}

A virgin 70/100 bitumen has been chosen because of the need of soften the aged bitumen present on the RA. The new aggregates are granite igneous rocks and the filler is limestone; the use of those aggregates was justified by the proximity of their sources to the laboratory and to the asphalt plant.

In terms of RA, the material results from milling off the surface layer of a highway pavement and was subsequently separated between a fine and a coarse fraction by a classifier with a mesh of $10 \mathrm{~mm}$. 


\subsection{Methods}

\subsubsection{Foamed Bitumen production process}

In this study, a Wirtgen WLB $10 \mathrm{~S}$ lab scale plant was used to produce the foamed bitumen, which injects water and air into hot bitumen in an expansion chamber, promoting the formation of bitumen foam. The equipment manufacturer mentioned that it has been developed to a laboratory scale with the objective of making the analysis of the FB characteristics in small scale possible, but it is similar to the equipment used in a normal scale (Wirtgen, 2008).

In order to increase the stability (measured by the half-life) of the foamed bitumen, a specific additive, already tested by other authors like Hailesilassie et al. (2015), was used. The air pressure was maintained at 5.5 bar (default value), the percentage of water used was $3 \%$ (by mass of bitumen) and the bitumen temperature was $150^{\circ} \mathrm{C}$.

\subsubsection{Selection of the mixing temperature}

Taking the importance of the mixing temperature to the production of WMAs into consideration and the need to better understand the role of foamed bitumen in the behavior of the mixtures, compactability and water sensitivity tests have been carried out. Thus, four mixtures were produced (with 30\% RA and foamed bitumen) at different temperatures. A control hot mix asphalt (HMA) mixture (with 30\% RA and a 70/100 pen virgin bitumen without being foamed) was also produced for comparison.

The production of the mixtures with incorporation of RA was carried out taking into account that further ageing of the bitumen present in the RA should be avoided. Thus, the fine RA fraction was introduced in the mixture at ambient temperature and only the new aggregates and the coarse RA fraction have been heated (Table 1). To mitigate the ageing effect of heating, the time during which the coarse RA fraction was submitted to high temperatures was limited to two hours.

Table 1. Reference and real temperatures of the mixtures produced.

\begin{tabular}{|c|c|c|c|c|c|c|}
\hline \multirow[t]{2}{*}{ Mixture } & \multirow{2}{*}{$\frac{\text { Ref. Temp. }}{{ }^{\circ} \mathrm{C}}$} & \multicolumn{5}{|c|}{ Real Temperatures $\left({ }^{\circ} \mathrm{C}\right)$} \\
\hline & & New aggregates & Coarse Fraction & Fine Fraction & Production & Compaction \\
\hline FB160 & 160.0 & 212.3 & 206.8 & 20.5 & 160.0 & 146.8 \\
\hline FB150 & 150.0 & 195.6 & 179.7 & 20.1 & 145.0 & 133.0 \\
\hline FB140 & 140.0 & 181.8 & 178.8 & 19.5 & 138.0 & 122.5 \\
\hline FB130 & 130.0 & 167.5 & 166.8 & 17.9 & 125.0 & 108.6 \\
\hline Control & 160.0 & 211.8 & 211.0 & 25.3 & 165.8 & 146.6 \\
\hline
\end{tabular}

In order to maintain the homogeneity of the specimens produced at each studied temperature (the bitumen content of the RA material and the amount of foamed bitumen injected by the foaming equipment may vary slightly amongst different samples), all specimens of a specific temperature were manufactured from the same batch ( 3 specimens for compactability tests and the other 6 for water sensitivity tests).

The compactability tests (EN 12697-10) were carried out using a Marshall Impact compactor (EN 12697-30) with a measuring device for automatically recording the thickness of the specimen after each compacting blow. The compaction of the specimens comprised the application of a total of 200 blows.

For the water sensitivity tests, 6 specimens were used in accordance with the EN 12697-12 standard, according to which, two groups of three specimens are tested for the indirect tensile strength (ITS) after a different conditioning period (three specimens are kept dry and the others three are kept in water). In this particular study, a curing period of 36 hours was used for all specimens prior to the tests, during which they were at room temperature. With this test it is possible to assess the loss of strength of the mixtures when in contact with water, by determining the ratio between the indirect tensile strength of the wet specimens and the dry specimens (ITSR), which is an indicator of the durability of the mixtures when applied in a real context. 


\section{RESULTS AND DISCUSSION}

\subsection{Foamed bitumen characteristics}

As previously mentioned, a foam promoting additive was used in this study. The main characteristics of the foamed bitumen produced with and without the additive are presented in Table 2. It can be observed that the expansion ratio (ERmax) is not significantly affected by the incorporation of the additive, but half-life (HL) has increased more than 4 times, which is a good advantage to the production of mixtures with this technique. The foam index (FI) obtained show the importance of the HL on the analysis of the expansion process, and prove the importance of the use of a foam promoting additive.

Table 2. Expansion characteristics of foamed bitumen.

\begin{tabular}{llll}
\hline Bitumen & ERmax & Half-life & Foam Index \\
\cline { 3 - 4 } & & sec & sec \\
\hline $70 / 100$ & 20.0 & 10.5 & 392.1 \\
$70 / 100+0.1 \%$ Additive & 17.0 & 47.3 & 671.5 \\
\hline
\end{tabular}

Both bitumens were also tested in terms of rheological characteristics and the higher limit PG grade of both bitumens was $64{ }^{\circ} \mathrm{C}$, confirming that the additive does not affect the properties of the virgin bitumen.

\subsection{Compactability test results}

The compactability test results show the evolution of the air void content of a specimen during the compaction process for a specific temperature. Repeating this procedure for a series of different temperatures is important to understand how the temperature may influence the workability of the mixture and, consequently, the porosity of the mixture. Based on the results obtained (Figure 1), it is possible to see that the difference in terms of air voids content is not significant for the mixtures produced with FB at 160 and $150{ }^{\circ} \mathrm{C}$. In fact the results are very similar to those of the control mixture. However, for the mixtures produced at 140 and $130{ }^{\circ} \mathrm{C}$, a higher air void content was obtained. In order to compare the results to those of the specimens prepared for the water sensitivity tests, the air void content should be measured after 150 blows, which is equivalent to the compaction energy used in the Marshall compaction by applying 75 blows in each face of the specimen, as presented in Table 3.

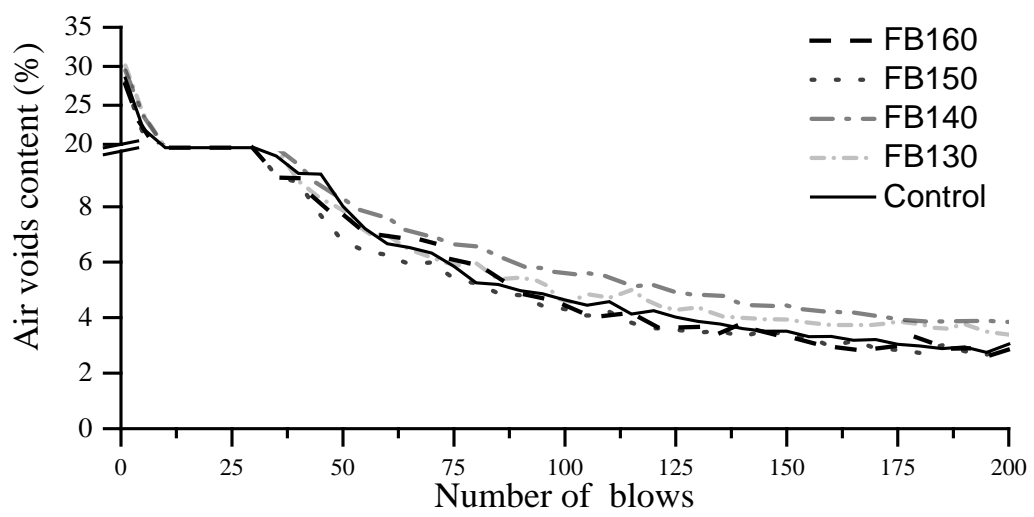

Figure 1. Compactability test results of the studied mixtures. 
Table 3. Air voids content of the specimens after 150 compacting blows.

\begin{tabular}{llllll}
\hline & FB160 & FB150 & FB140 & FB130 & Control \\
\hline Air voids content (\%) & 3.3 & 3.4 & 4.4 & 3.9 & 3.5 \\
\hline
\end{tabular}

\subsection{Water sensitivity test results}

The value of air voids content is closely related to the water sensitivity of asphalt mixtures. Thus, all specimens used for this test were also volumetrically characterized (Table 4). As can be observed, the results obtained are similar to those of the compactability test specimens. The main differences are observed for the FB130 mixture, as a result of the lower production temperature.

Table 4. Air voids content of the specimens used in the water sensitivity tests.

\begin{tabular}{llllll}
\hline & FB160 & FB150 & FB140 & FB130 & Control \\
\hline Air voids content (\%) & 3.5 & 3.1 & 4.7 & 4.9 & 3.2 \\
\hline
\end{tabular}

The water sensitivity test results are shown in Figure 2, where it is possible to see that the ITSR values of the mixtures produced with foamed bitumen are slightly more influenced by the presence of water than the control mixture. Nevertheless, the results obtained for the mixtures produced at $140{ }^{\circ} \mathrm{C}$ and above showed very interesting ITSR values (above 85\%). The lower ITSdry values of the mixtures produced at 140 and $130{ }^{\circ} \mathrm{C}$ may be related to the higher air void contents of those mixtures, even though it did not significantly affect the ITSR of the FB140 mixture. Thus it can be concluded that it is possible to produce recycled asphalt mixtures with $30 \%$ RA with foamed bitumen, reducing the production temperature by $20^{\circ} \mathrm{C}$ without significantly affecting the volumetric properties of the mixtures and their water susceptibility.

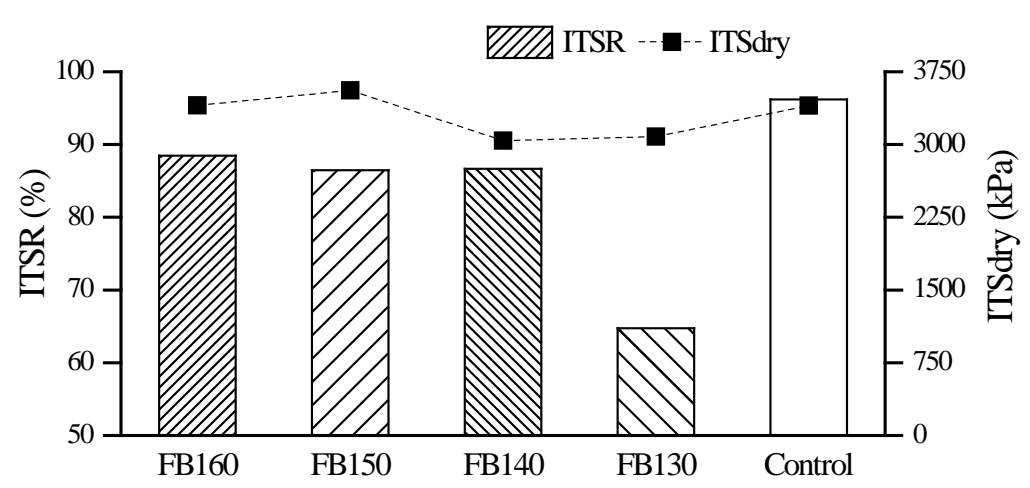

Figure 2. Water sensitivity test results.

\section{CONCLUSIONS}

The use of foamed bitumen in the production of asphalt mixtures with incorporation of $30 \%$ RA material have been tested and the results show that this technique could be a good option to reduce the production temperatures of this type of mixtures.

Up to a reduction of $20^{\circ} \mathrm{C}$ on the production temperatures, the mixtures with foamed bitumen showed similar properties to those of the control mixture produced with conventional hot bitumen. Thus it can be concluded that this type of binder can be efficient in reducing the production temperature of mixtures with RA incorporation, reducing the possibility of inducing undesirable ageing on the bitumen present in the RA material which is already hard and brittle. 


\section{ACKNOWLEDGMENT}

The authors would like to acknowledge the contribution of the companies Galp and Elevo Group, who provided the binders and the RAP used in this study. This work is being funded by ERDF funds through the Operational Competitiveness Program - COMPETE in the scope of Project "Energy Efficiency and Environmental Design of Bituminous Mixtures and Reducing Emissions of Greenhouse Gases" (SI Innovation Project 7603). Thanks are also due to the Foundation for Science and Technology (FCT) for funding allocated through the $\mathrm{PhD}$ grant SFRH/BD/85448/2012.

\section{REFERENCES}

Abreu, L. P. F., Oliveira, J. R. M. \& Silva, H. M. R. D. 2013. Formulação e caracterização de ligantes numa mistura betuminosa com uma taxa de reciclagem elevada. $7^{\circ}$ Congresso Rodoviário Português. Lisboa.

Abreu, L. P. F., Oliveira, J. R. M., Silva, H. M. R. D. \& Fonseca, P. V. 2015. Recycled asphalt mixtures produced with high percentage of different waste materials. Construction and Building Materials, 84, 230-238.

Aravind, K. \& Das, A. 2007. Pavement design with central plant hot-mix recycled asphalt mixes. Construction and Building Materials, 21, 928-936.

Brennen, M., Tia, M., Altschaeffl, A. G. \& Wood, L. E. 1983. Laboratory investigation of the use of foamed asphalt for recycled bituminous pavements. Transportation Research Record p. 80-87.

Celauro, C., Bernardo, C. \& Gabriele, B. 2010. Production of innovative, recycled and high-performance asphalt for road pavements. Resources, Conservation and Recycling, 54, 337-347.

Chiu, C.-T., Hsu, T.-H. \& Yang, W.-F. 2008. Life cycle assessment on using recycled materials for rehabilitating asphalt pavements. Resources, Conservation and Recycling, 52, 545-556.

D’angelo, J., Harm, E., Bartoszek, J., Baumgardner, G., Corrigan, M., Cowsert, J., Harman, T., Jamshidi, M., Jones, W., Newcomb, D., Prowell, B., Sines, R. \& Yeaton, B. 2008. Warm-Mix Asphalt: European Practice. Alexandria.

Hailesilassie, B., Schuetz, P., Jerjen, I., Hugener, M. \& Partl, M. 2015. Dynamic X-ray radiography for the determination of foamed bitumen bubble area distribution. Journal of Materials Science, 50, 79-92.

He, G. \& Wong, W. 2006. Decay properties of the foamed bitumens. Construction and Building Materials, 20, 866-877.

He, G. \& Wong, W. 2007. Laboratory study on permanent deformation of foamed asphalt mix incorporating reclaimed asphalt pavement materials. Construction and Building Materials, 21, 18091819.

Jenkins, K. J. 2000. Mix Design Considerations for Cold and Half-warm Bitumen Mixes with Emphasis on Foamed Bitumen Doctor of Philosophy (Engineering), University of Stellenbosch.

Oliveira, J. R. M., Silva, H. M. R. D., Abreu, L. P. F. \& Pereira, P. a. A. 2012. Effect of Different Production Conditions on the Quality of Hot Recycled Asphalt Mixtures. Procedia - Social and Behavioral Sciences, 53, 266-275.

Palha, D., Fonseca, P., Abreu, L. P. F., Oliveira, J. R. M. \& Silva, H. M. R. D. 2013. Solutions to improve the recycling rate and quality of plant produced hot mix asphalt. 2nd International Conference WASTES: solutions, treatments, opportunities. Braga.

Rubio, M. C., Martínez, G., Baena, L. \& Moreno, F. 2012. Warm mix asphalt: an overview. Journal of Cleaner Production, 24, 76-84.

Sengoz, B., Topal, A. \& Gorkem, C. 2013. Evaluation of natural zeolite as warm mix asphalt additive and its comparison with other warm mix additives. Construction and Building Materials, 43, 242-252.

Shu, X., Huang, B., Shrum, E. D. \& Jia, X. 2012. Laboratory evaluation of moisture susceptibility of foamed warm mix asphalt containing high percentages of RAP. Construction and Building Materials, 35, 125-130.

Su, K., Hachiya, Y. \& Maekawa, R. 2009. Study on recycled asphalt concrete for use in surface course in airport pavement. Resources, Conservation and Recycling, 54, 37-44.

Wirtgen 2008. Suitability test procedures of foam bitumen using Wirtgen WLB 10 S. Germany: Wirtgen, $\mathrm{GmbH}$

Zaumanis, M., Haritonovs, V., Brencis, G. \& Smirnovs, J. 2012. Assessing the Potential and Possibilities for the Use of Warm Mix Asphalt in Latvia. Construction Science, 13, pp. 6-59. 